\title{
Mulheres no cárcere: Uma revisão de literatura sobre a realidade das mulheres encarceradas
}

\author{
Women in Jail: a literature review on the reality of women in charge
}

\section{Mujeres en la Cárcel: una revisión de literatura sobre la realidad de las mujeres encargadas}

\author{
Izani Gonçalves dos Santos ${ }^{1}$ https://orcid.org/0000-0003-0809-3902 \\ Isaias Pereira da Silva ${ }^{2}$ https://orcid.org/0000-0002-3506-0738 \\ Yata Anderson Gonzaga Masullo ${ }^{3}$ https://orcid.org/0000-0001-5861-752X
}

\begin{abstract}
${ }^{1}$ Graduação em Geografia pela Universidade Federal do Maranhão (UFMA) - São Luís - MA - Brasil - Auxiliar de Pesquisa do Instituto Maranhense De Estudos Socioeconômicos E Cartográficos (IMESC). Email: izani.gds@gmail.com.

${ }^{2}$ Graduação em Geografia pela Universidade Federal do Maranhão (UFMA) - São Luís - MA - Brasil - Programa de Pósgraduação em Saúde Coletiva (PPGSC). Email: isaiassilva158@gmail.com.

${ }^{3}$ Doutor em Geografia pela Universidade de Brasília - UNB - São Luís - MA - Brasil - Pesquisador do Instituto Maranhense de Estudos Socioeconômicos e Cartográficos - IMESC. Email: yanderson3@ hotmail.com.
\end{abstract}

Recebido em: 27/06/2020

Aceito para publicação em: 30/09/2020

\begin{abstract}
Resumo
O aumento das mulheres encarceradas nos sistemas prisionais crescem exponecialmente nas últimas décadas. Embora com participação reduzida em relação aos homens na criminalidade, há violação e desigualdade de seus direitos, e invisibilidade das políticas públicas que deveriam garantir o seu regresso a sociedade em condições adequadas. Nesse contexto, objetiva-se compreender a realidade e as singularidades do sistema carcerário feminino no Brasil e no mundo. O presente estudo desenvolveu extensa revisão de literatura, com base em estudos científicos sobre as mulheres encarceradas. A pesquisa desenvolvida, identificou a necessidade da implementação de diferentes metodologias que visam avaliar a realidade das mulheres encarceradas, bem como o desenvolvimento e redirecionamento de políticas públicas ligadas as mulheres nos sistemas prisionais e setores da sociedade.
\end{abstract}

PALAVRAS-CHAVE: Violência. Cárcere. Mulher.

\footnotetext{
Abstract

The increase in incarcerated women in prison systems has grown exponentially in recent decades. Although with reduced participation in relation to men in crime, there is a violation and inequality of their rights, and invisibility of public policies that should guarantee their return to society in adequate conditions. In this context, the objective is to understand the reality and the singularities of the female prison system in Brazil and in the world. The present study has developed an extensive literature review, based on scientific studies on incarcerated women. The research developed, identified the need to implement different methodologies that aim to assess the reality of incarcerated women, as well as the development and redirection of public policies related to women in prison systems and sectors of society.
}

Geopauta, Vitória da Conquista, ISSN: 2594-5033, V. 4, n.3, 2020, p.(255-273) http://periodicos2.uesb.br/index.php/geo, 
KEYWORD: Violence. Prison. Woman.

\section{Resumen}

El aumento de las mujeres encarceladas en los sistemas penitenciarios ha crecido exponencialmente en las últimas décadas. Aunque con una participación reducida en relación con los hombres en el crimen, existe una violación y desigualdad de sus derechos, y la invisibilidad de las políticas públicas que deberían garantizar su retorno a la sociedad en condiciones adecuadas. En este contexto, el objetivo es comprender la realidad y las singularidades del sistema penitenciario femenino en Brasil y en el mundo. El presente estudio ha desarrollado una extensa revisión de la literatura, basada en estudios científicos sobre mujeres encarceladas. La investigación desarrollada identificó la necesidad de implementar diferentes metodologías que tengan como objetivo evaluar la realidad de las mujeres encarceladas, así como el desarrollo y la redirección de políticas públicas relacionadas con las mujeres en los sistemas penitenciarios y sectores de la sociedad.

PALABRA CLAVE: Violencia. Prisión. Mujer.

\section{Introdução}

Em todo o mundo, a violência é um dos principais contribuintes para mortes por causas externas, doenças e uma série de outras consequências sociais e de saúde (OMS, 2014). Esse fenômeno complexo, não se limita as barreiras geográficas, classes sociais e/ou períodos históricos.

A compreensão da violência urbana e o contexto acerca dos sistemas prisionais, estão intrínsecas as relações históricas e territoriais. Sendo que a sociedade vive amedrontada com o crescimento da violência, e espera que a prisão em massa seja a solução (JORGE, 2009). Nesse contexto, observa-se singularidades entre as mulheres aprisionadas, que além de transcender questões como relações de gênero, direitos humanos, segurança pública, saúde coletiva e desigualdades sociais, nos sistemas prisionais há em sua maioria em parte omissão de políticas públicas capazes de assegurar direitos naturais e as necessidades básicas das mulheres apenadas.

Considerando o exposto, o presente estudo propõe-se a contextualizar e ampliar a compreensão da realidade que vivem as mulheres nos sistemas prisionais nas diferentes regiões do Brasil e do Mundo. Para tanto, inicia-se caracterizando o sistema prisional a partir da revisão de literatura de estudos científicos desenvolvidos na última década, por meio do portal de periódicos da CAPES (Coordenação de Aperfeiçoamento de Pessoal de Nível Superior), SCIELO e Google Acadêmico, divido em 25 artigos abrangendo a realidade brasileira e 25 relativos a artigos internacionais. Posteriormente, analisa-se pesquisas sobre a realidade das mulheres encarceradas, a partir de informações ligadas ao tema; recorte espacial e metodologia aplicada. 


\section{O sistema prisional no Brasil e o contexto internacional}

No Brasil, as punições sob forma de pena são tão antigas quanto sua história, remontando desde os períodos coloniais escravistas com atenção as punições corporais aplicadas aos escravos. Contudo, apenas a partir do século XIX que se estrutura o sistema prisional, semelhante aos estabelecimentos atuais com a Casa de Correção do Rio de Janeiro em 1850, como expõe Machado et. al. (2013, p. 203) "no Brasil, foi a partir do século XIX que se deu início ao surgimento de prisões com celas individuais e oficinas de trabalho, bem como arquitetura própria para a pena de prisão”.

Atualmente, o sistema carcerário brasileiro é regulamentado pela Lei de $\mathrm{n}^{\circ} 7.210$, de julho de 1984 do Código Penal, a Lei de Execuções Penais (LEP), com os principais tipos de estabelecimentos penais: Cadeias Públicas, Casas do Albergado, Penitenciárias, Colônias Agrícolas, Industriais ou Similares, Patronatos, Hospitais de Custódia e Tratamento Psiquiátrico (OLIVEIRA, 2007). Esse instrumento preconiza como deve ser executada a pena de privação de liberdade e restrição de direitos no Brasil.

O dispositivo legal supracitado reforça a finalidade da ressocialização nos estabelecimentos prisionais, bem como assegura a recreação, assistência à saúde, jurídica, educação adequadas, alimentação e vestuários suficientes aos apenados. No entanto, observase grande disparidade entre as ferramentas legais e os instrumentos do cárcere.

Como reflexo desse contexto, verifica-se superlotações, sucateamento estrutural, contínuos episódio de rebeliões, disputa entre facções dentro e fora dos presídios, resultando no aumento da violência e insegurança. Dados do Departamento Penitenciário Nacional (DEPEN,2019), retratam essa conjuntura, em que a população carcerária brasileira supera a quantidade disponível de vagas (442.000), com aproximadamente 755.200 pessoas restrição de liberdade em 2020. Isso demonstra o quadro de precariedade que o sistema carcerário nacional vivencia.

A realidade exposta, afeta significativamente todo o sistema prisional e de forma específica as mulheres. Nesse contexto, destacam-se questões como a maternidade, desigualdade de gênero, violências físicas, psíquica, emocional.

Sendo este, portanto, um dos inúmeros problemas relacionados a superlotação que atinge principalmente as prisões brasileiras. Entretanto, tal situação é possível de se remediar, acentuando-se a exemplo os presídios holandeses com baixíssima lotação como ressalta 
Rudnicki (2016). O autor utiliza como exemplo de boas práticas, a Penitenciária Feminina Madre Pelletier no Estado do Rio Grande do Sul, que através de ações conjuntas entre diferentes agentes de transformação social, busca solucionar a superlotação do presídio, a partir da situação de convívio entre as apenadas.

Mesmo com penitenciárias com exemplos exitosos, a problemática do superencarceramento ainda está longe de ser uma realidade para todo o país. A seguir, refletimos de forma específica sobre a realidade das mulheres no sistema prisional e as ações sociais por meio das políticas públicas.

\section{Mulheres no cárcere}

Dados do World Prision Brief (WPB, 2017), mostram que o sistema prisional feminino em 2017, registrava mundialmente mais de 700 mil mulheres e meninas em regime fechado, semiaberto, preventivo. Os Estados Unidos lideram esse rank com um total de 211. 810 presas, em seguida, estão a China com 107 mil mulheres encarceradas, até a última atualização da lista mundial de prisioneiras mulheres ${ }^{1}$. Em terceiro a Rússia com 48.478, e Brasil com cerca de 44.700 mulheres privadas de sua liberdade, principalmente pelo crime de tráfico de drogas (RUEDIGER e SANCHES, 2018).

Gráfico 1 - Proporção de mulheres encarcerados por delitos de drogas na América Latina.

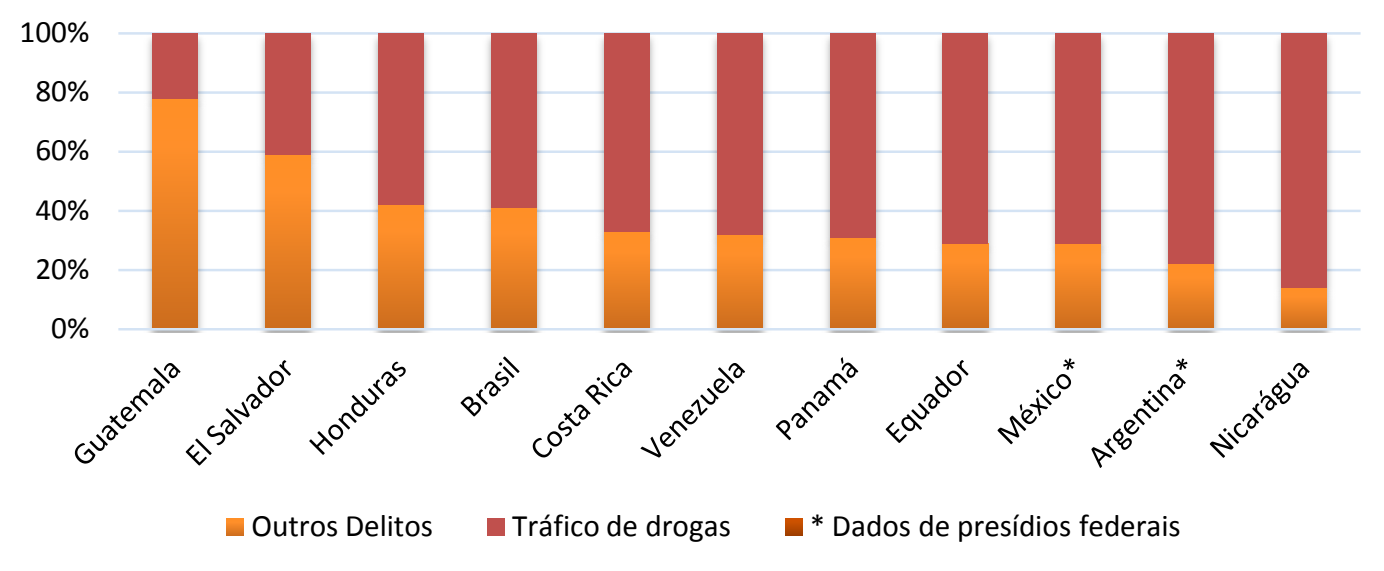

Fonte: IDPC, 2013

O crime mais cometido por mulheres encarceradas no mundo é o tráfico de drogas, acompanhado dos crimes de associação ao tráfico, roubo, furto, e em menor proporção homicídio e latrocínio (DEPEN, 2017). Conforme o INFOPEN Mulheres (2017) e International Drug Policy Consortium (IDPC, 2013) no Brasil e na América Latina, 50\% das

\footnotetext{
${ }^{1}$ Lista Mundial de Prisioneiros Femininos e Lista Mundial de Populações Prisionais estão disponíveis em: www.prisonstudies.org.

Geopauta, Vitória da Conquista, ISSN: 2594-5033, V. 4, n.3, 2020, p.(255-273) http://periodicos2.uesb.br/index.php/geo, 
mulheres encarceradas estão na faixa etária de 18 a 29 anos, 62\% são solteiras, aproximadamente $80 \%$ são mães solteiras e cerca de $62 \%$ possuem envolvimento com tráfico de drogas (Gráfico 1).

Na Argentina, Brasil e Costa Rica mais de $60 \%$ da população carcerária feminina possui restrição de liberdade por delitos relacionados a drogas (Tabela 1). Como relatado anteriormente, significativa parcela possui baixo nível educacional, vivem em condições de vulnerabilidade social e possuem dependentes (WOLA, 2018).

Tabela 1 - Mulheres encarceradas por crimes relacionado a drogas.

\begin{tabular}{|c|c|c|}
\hline País & $\begin{array}{c}\text { Número de mulheres encarceradas por } \\
\text { crimes relacionados a drogas }\end{array}$ & $\begin{array}{c}\text { Porcentagem de mulheres encarceradas } \\
\text { por crimes relacionados a drogas }\end{array}$ \\
\hline Argentina & 790 & $65 \%$ \\
\hline \multicolumn{3}{|c|}{ Estatística das prisões federais, 2013} \\
\hline Brasil & 16.489 & $60,63 \%$ \\
\hline \multicolumn{3}{|c|}{ Junho de 2013} \\
\hline Colômbia & 3.830 & $45 \%$ \\
\hline \multicolumn{3}{|c|}{2014} \\
\hline Costa Rica & 944 & $75,46 \%$ \\
\hline \multicolumn{3}{|c|}{ Dezembro de 2011} \\
\hline Chile & 1.889 & $57,20 \%$ \\
\hline \multicolumn{3}{|c|}{ Baseado na população de abril de 2015} \\
\hline \multirow{2}{*}{\multicolumn{3}{|c|}{2015}} \\
\hline & & \\
\hline México & $\begin{array}{l}\text { Federal } 528 \\
\text { Local } 1.547\end{array}$ & $\begin{array}{l}44,80 \% \\
14,20 \%\end{array}$ \\
\hline \multicolumn{3}{|c|}{ Agosto2014/Maio2013 } \\
\hline Peru & 2.679 & $60,60 \%$ \\
\hline \multicolumn{3}{|c|}{2014} \\
\hline Uruguai & 126 & $\mathbf{2 9 , 5 0 \%}$ \\
\hline & 2014 & \\
\hline
\end{tabular}

Fonte: WOLA, 2018.

Sob o contexto apresentado, Boiteux (2016, p.5) afirma "A maioria destas mulheres vêm de estratos sociais mais marginalizados e excluídos socialmente, e não tem os meios financeiros ou o conhecimento jurídico ou de capital para fornecer-se com a defesa jurídica adequada." Ramos destaca (2010) que quando o parceiro é preso a mulher dificilmente lhe abandona neste período de sua vida, mas quando é o inverso, dificilmente o parceiro mantém a relação de afetividade pela mulher.

As mulheres encarceradas são majoritariamente esquecidas nos sistemas prisionais, e recebem o rigor do sistema de justiça criminal aos processos criminais do tráfico: a dosimetria desproporcional, execução da pena em desacordo com os direitos reconhecidos aos indivíduos privados da liberdade, além da ausência em sua maioria do benefício da visita íntima, distanciamento dos familiares e separação dos filhos (MACHADO, 2016).

Ao mesmo tempo, que se observa o menor quantitativo comparado aos homens, os dados oficiais expõem um crescimento em massa de mulheres encarceradas ao longo das 
últimas décadas. Santoro e Pereira (2018, p. 90) apontam que "O percentual de mulheres encarceradas é menor comparativamente aos homens, contudo, a reduzida presença numérica das mulheres não pode ser usada como justificativa para a violação de seus direitos.”.

A maior parcela das penitenciarias brasileiras foram criadas e destinadas para a população masculina, moldando-se ao longo das últimas décadas ao aumento exponencial das mulheres encarceradas. Segundo a Pastoral Carcerária (2015), no Brasil há 508 estabelecimentos penitenciários com mulheres encarceradas; desse universo somente 58 são exclusivamente estabelecimentos femininos, e 450 são compartilhadas entre os homens e mulheres.

Segundo o INFOPEN Mulheres do Departamento Penitenciário Nacional (DEPEN, 2017), em 2017 a população prisional feminina atingiu a marca de 38 mil mulheres aprisionadas, correspondendo a um aumento da população feminina de 656,5\% em relação a 2000, quando registrava-se aproximadamente 6 mil mulheres apenadas (Gráfico 02).

Gráfico 2 - Evolução do quantitativo de mulheres privadas de liberdade (em mil) entre 2000 e 2017.

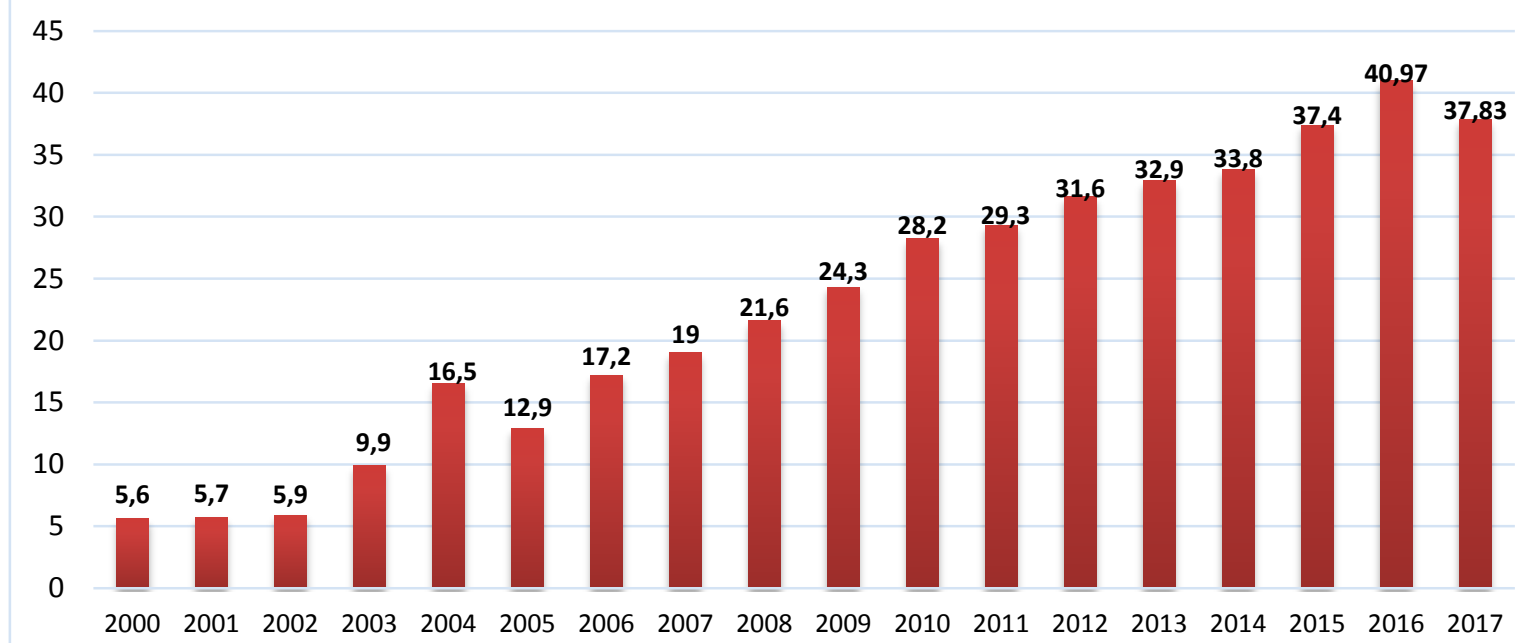

Fonte: INFOPEN Mulheres (DEPEN, 2017).

Nesse sentido, verificam-se que essa realidade poderia ser amenizada com a ampliação de programas direcionada ao enfretamento mais eficaz por meio das políticas contra as drogas, políticas públicas que visam a ressocialização dos presos e presas com o objetivo de instrui-los há uma profissão e/ou ocupação, e com isso ao saírem das prisões, mostrariam maior resiliência, reduzindo a possibilidade de regressar aos estabelecimentos prisionais.

\section{RESULTADOS E DISCUSSÕES}


Com base na revisão bibliográfica realizada, foram produzidos quadros sínteseanalíticos, relacionados ao contexto de mulheres presas no sistema brasileiro e internacional. O Quadro 01 a seguir, relaciona a ordem, título e autor, recorte espacial do estudo, metodologia e resultados e conclusões obtidas dos trabalhos analisados.

Quadro 1 - Quadro de síntese dos artigos nacionais

\begin{tabular}{|c|c|c|}
\hline $\begin{array}{c}\text { Ano de } \\
\text { publicação }\end{array}$ & Título e Autor & Recorte do estudo e Metodologia \\
\hline 2010 & $\begin{array}{c}\text { Mulheres encarceradas: elas, seus filhos e } \\
\text { nossas políticas } \\
\text { (FERRARI, F.I.) }\end{array}$ & $\begin{array}{l}\text { Belo Horizonte (Minas Gerais) } \\
\text { Pesquisas bibliográficas }\end{array}$ \\
\hline 2010 & $\begin{array}{l}\text { Sistema prisional: conhecendo as vivências da } \\
\text { mulher inserida neste contexto } \\
\text { (MINZON, ET AL.) }\end{array}$ & $\begin{array}{l}\text { Estudo desenvolvido na Universidade Paranaense- } \\
\text { Paraná } \\
\text { Pesquisas bibliográficas }\end{array}$ \\
\hline 2010 & $\begin{array}{l}\text { Ressocialização: o desafio da educação no } \\
\text { sistema prisional feminino } \\
\text { (CUNHA, E.) }\end{array}$ & $\begin{array}{c}\text { Estudo desenvolvido no Centro de Ressocialização } \\
\text { Feminino (CRF) de Araraquara (Minas Gerais), } \\
\text { mas pela Universidade Estadual Paulista } \\
\text { Questionários, entrevistas e bibliografias }\end{array}$ \\
\hline 2010 & $\begin{array}{l}\text { Mulheres encarceradas e fatores associados a } \\
\text { drogas e crimes (LOPES, ET AL.) }\end{array}$ & $\begin{array}{c}\text { Presídio no Rio Grande do Sul } \\
\text { Estudo quantitativo e transversal }\end{array}$ \\
\hline 2012 & $\begin{array}{c}\text { Desigualdade de Gênero no Sistema Prisional: } \\
\text { Considerações Acerca das Barreiras à } \\
\text { Realização de visitas e visitas Íntimas às } \\
\text { Mulheres Encarceradas } \\
\text { (OLIVEIRA, M. G.F \& SANTOS, A.F.R.) }\end{array}$ & $\begin{array}{l}\text { Recorte Nacional } \\
\text { Basearam-se em pesquisa bibliográfica }\end{array}$ \\
\hline 2012 & $\begin{array}{c}\text { Sistema prisional brasileiro sob a perspectiva de } \\
\text { gênero: invisibilidade e desigualdade social da } \\
\text { mulher encarcerada (MIYAMOTO, Y. \& } \\
\text { KROHLING, A.) }\end{array}$ & $\begin{array}{l}\text { Estudo no Espírito Santo } \\
\text { Pesquisa histórico-dialética }\end{array}$ \\
\hline 2014 & $\begin{array}{l}\text { Teatro-Menor: Cartografia em arte e } \\
\text { experimentação de mulheres em situação de } \\
\text { cárcere (SOARES, ET AL.) }\end{array}$ & $\begin{array}{c}\text { Presídio Feminino do Rio Grande do Norte } \\
\text { Utilizaram para o estudo a observação participante, } \\
\text { oficinas em teatro-experimentação }\end{array}$ \\
\hline 2015 & $\begin{array}{l}\text { A (in)visibilidade da mulher criminosa e a } \\
\text { desigualdade de gênero no espaço da prisão: } \\
\text { uma análise da vivência das mulheres em } \\
\text { situação de prisão no Complexo Penal } \\
\text { Estadual Agrícola Dro Mário Negócio em } \\
\text { Mossoró/RN (NASCIMENTO, L.C.S.) }\end{array}$ & $\begin{array}{c}\text { Mossoró - Rio Grande do Norte } \\
\text { Pesquisa qualitativa e bibliográfica, observação } \\
\text { participante }\end{array}$ \\
\hline 2016 & $\begin{array}{l}\text { Atrás das grades: questões de gênero na prisão } \\
\text { feminina de João Pessoa } \\
\text { (LAIER, M.G.S.) }\end{array}$ & $\begin{array}{l}\text { Prisão Feminina de João Pessoa } \\
\text { Pesquisa bibliográfica, observação participante. }\end{array}$ \\
\hline 2016 & $\begin{array}{l}\text { Condições Precárias de Saúde na Ala Feminina } \\
\text { do Presídio Nilton Gonçalves: Uma História de } \\
\text { Abandono e Sofrimento (TOURINHO, et. Al.) }\end{array}$ & $\begin{array}{l}\text { Vitória da Conquista/Bahia } \\
\text { Pesquisa qualitativa e bibliográfica, com } \\
\text { entrevistas estruturadas. }\end{array}$ \\
\hline 2016 & $\begin{array}{l}\text { Criminalidade Feminina: Desestabilidade } \\
\text { familiar e as várias faces do abandono } \\
\text { (DAVIM, B. K. G. \& LIMA, C.S.) }\end{array}$ & $\begin{array}{l}\text { Recorte Nacional } \\
\text { Estudo baseado em pesquisa bibliográfica }\end{array}$ \\
\hline 2017 & $\begin{array}{l}\text { Mulheres e criminalidade: } \\
\text { Aspectos de uma inclusão enviesada } \\
\text { (SILVA, S.L.) }\end{array}$ & $\begin{array}{l}\text { Estado do Rio Grande do Norte } \\
\text { Estudo realizado por extensão universitária e } \\
\text { revisão bibliográfica. }\end{array}$ \\
\hline & Rés negras, juízes brancos: Uma análise da & Penitenciária Feminina de Sant'Ana (PFS), na \\
\hline
\end{tabular}

Geopauta, Vitória da Conquista, ISSN: 2594-5033, V. 4, n.3, 2020, p.(255-273) http://periodicos2.uesb.br/index.php/geo, 
2017

interseccionalidade de gênero, raça e classe na produção da punição em uma prisão paulistana

(ALVES, D.)

2017 Contribuições feministas para os estudos acerca do aprisionamento de mulheres

(CARVALHO, ET AL.)

2017 Mulheres nas prisões brasileiras: tensões entre a ordem disciplinar punitiva e as prescrições da maternidade

(DIUANA, ET AL)

2018 Violência contra a mulher, polícia civil e políticas pública.

(SOUZA, ET AL.)

Mulheres no crime: análise sobre enunciados

2018

(CARVALHAES, ET AL.)

Processos de criminalização e a participação feminina no tráfico de drogas.

(CARVALHO, J.)

Narrativas sobre experiências de leitura em uma cadeia pública feminina: fronteiras borradas

(WILLMS, et. Al.) cidade de São Paulo

Estudo realizado a partir de consultas a processos judiciais e prontuários criminológicos, entrevistas semiestruturadas com mulheres negras encarceradas, e trabalho etnográfico

Estado de Minas Gerais

Coletaram dados diretamente no Conselho Nacional de Justiça.

Pesquisa bibliográfica

\section{Recorte Nacional}

Pesquisa desenvolvida por meio de questionários enviado as unidades penitenciarias dos Estados

Estado de Goiás (Universidade Federal de Goiás)

Pesquisa empírica e de natureza qualitativa, com uso de entrevistas semiestruturadas com profissionais atuantes em DEAM; Recorte Nacional

Adotaram a abordagem qualitativa e a análise documental em documentos de domínio público (jornais)

Conjunto Penal

Feminino de Salvador, Bahia

Estudos empíricos, entrevista, e pesquisa bibliográfica

Cadeia Pública Feminina de Rondonópolis (Mato Grosso)

Pesquisa participante, de base antropológica

Quem está no comando? Mulher de bandido e

2019 os paradoxos da submissão (CÚNICO, ET AL.)
Presídio no Rio Grande do Sul

Utilizaram observação participante, entrevistas semiestruturadas

Presidio no estado do Espirito Santo

Levantamento dos dados contidos nos Relatórios

Estatístico-Analíticos do Sistema Prisional do

Departamento Penitenciário Nacional Revisão bibliográfica Recorte Nacional

\section{Recorte Nacional}

Adota-se o método dialético de abordagem, as técnicas de revisão bibliográfica e de pesquisa jurisprudencial, adotando a criminologia crítica como marco teórico.

Prisões de Curitiba

A metodologia adotada é a revisão bibliográfica, e também a análise documental, que estuda cartas de mulheres privadas de liberdade destinadas a

pessoas próximas e entrevistas realizadas no ano de 2017, na cidade de Curitiba

Prisões de Curitiba

De abordagem qualitativa, esta pesquisa empírica articula algumas categorias analíticas extraídas da investigação a partir da técnica de Análise do Conteúdo (BARDIN, 2011). 
Fonte: Elaborado pelos autores, 2019.

Entre as principais metodologias (Gráfico 03) utilizadas para compreender a temática das mulheres encarceradas no Brasil, evidenciou-se que há um predomínio das pesquisas de abordagem bibliográfica/documental com 40\%, seguidas das pesquisas quantitativa/qualitativas $24 \%$; artigos com abordagem etnográfica com $4 \%$.

Gráfico 3 - Percentual de cada método utilizados nos artigos

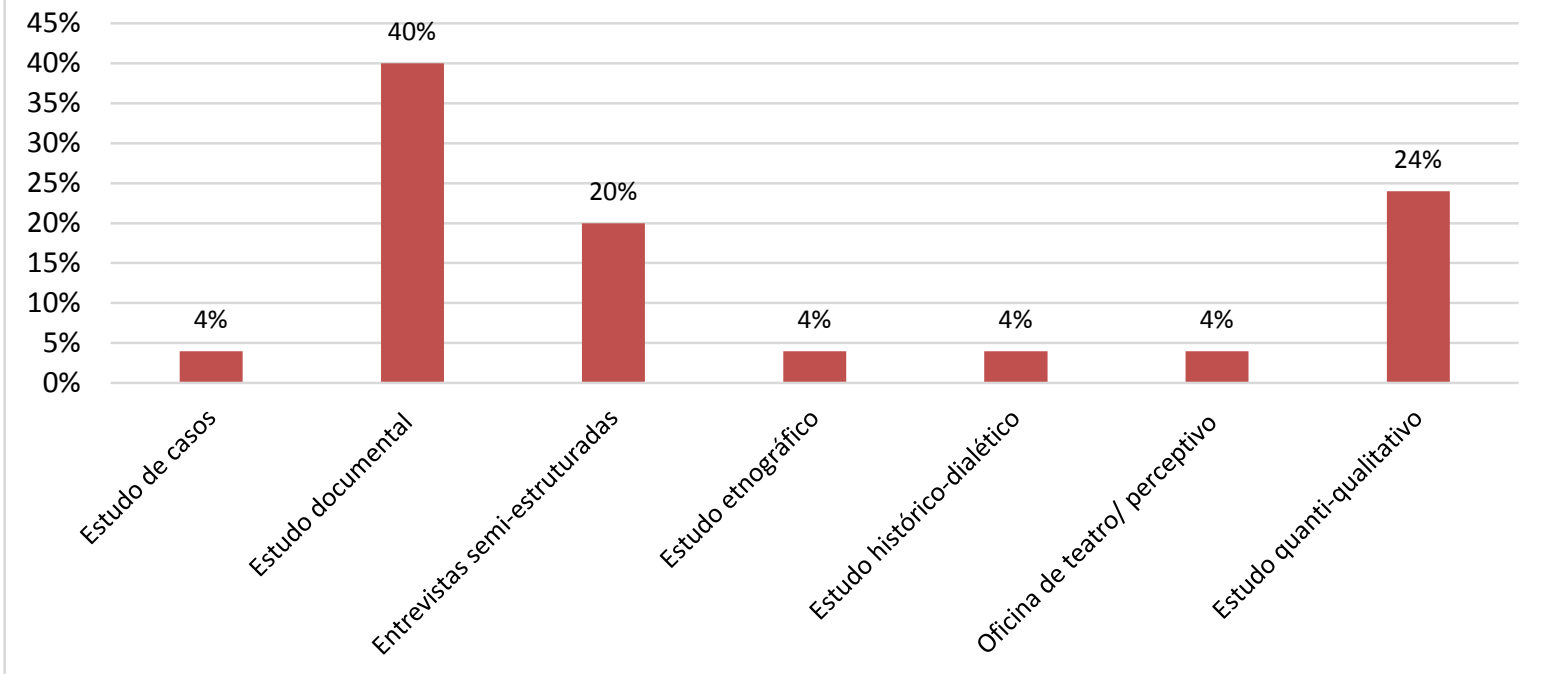

Fonte: Elaborado pelos autores, 2020.

Em relação a região brasileira, com o maior número de pesquisas estruturadas na amostra de estudos coletados, destaca-se as regiões sudeste e sul. Verifica-se que $24 \%$ das pesquisas selecionadas estão concentrados na região sudeste, principalmente do Estado de Minas Gerais, a região sul com $20 \%$ nos Estados do Paraná e Rio Grande do Sul. A região nordeste, apresentou 18\% dos estudos analisados, concentrando-se no Rio Grande do Norte e na Bahia. Já as regiões Centro-Oeste e Norte, foram apresentaram menos trabalhos identificados nesta pesquisa. Salientando-se que os estudos foram coletados de maneira aleatória, sem seleção das localidades (Gráfico 4).

Gráfico 4 - Percentual de estudos por regiões.

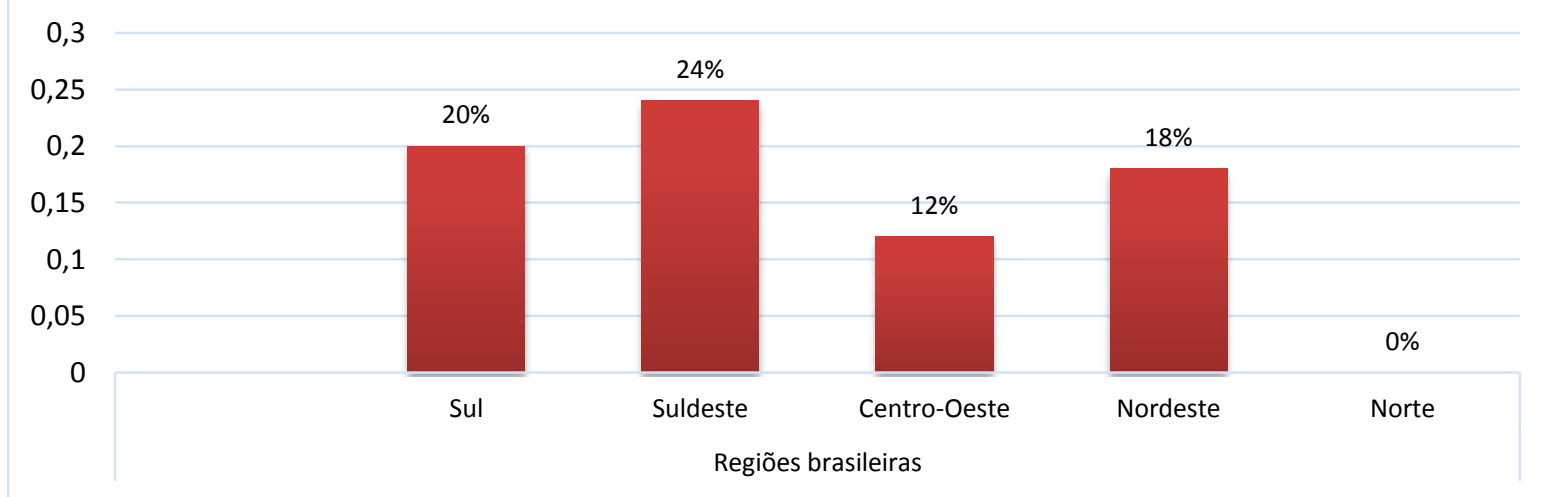

Geopauta, Vitória da Conquista, ISSN: 2594-5033, V. 4, n.3, 2020, p.(255-273) http://periodicos2.uesb.br/index.php/geo, 
Fonte: Elaborado pelos autores, 2020. Levantamento bibliográfico (2018-19)

Quanto as pesquisas internacionais selecionadas, constatou-se que dos 25 artigos internacionais, $8 \%$ dos estudos analisaram o recorte global, $32 \%$ concentrou-se nos Estados Unidos da América (EUA). Países como o Brasil, Reino Unido, México, Irlanda, Nova Zelândia, Israel, África Subsaariana e Argentina aparecem com 1 artigo cada (Gráfico 05; Quadro 02).

Gráfico 5 - Percentual de estudos por regiões.

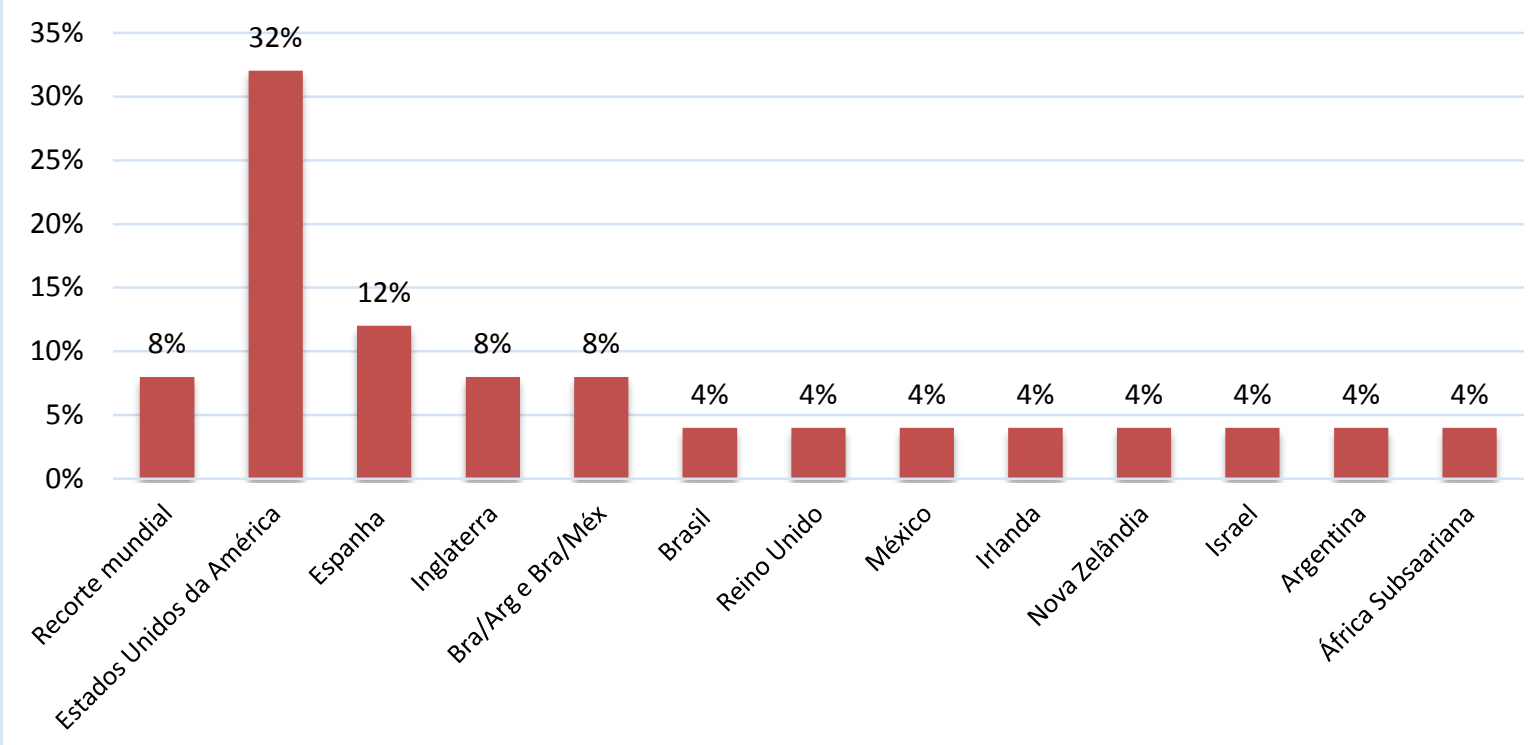

Fonte: Elaborado pelos autores, 2020. Levantamento bibliográfico (2018-19)

Quadro 2 - Quadro de síntese dos artigos internacionais

\begin{tabular}{|c|c|c|}
\hline $\begin{array}{c}\text { Ano da } \\
\text { publicação }\end{array}$ & Título e Autor & Recortes dos estudos e Metodologia \\
\hline 2010 & $\begin{array}{l}\text { Randomized } \\
\text { experimental study to treat gender- } \\
\text { sensitive substance abuse for women in } \\
\text { prison (MESSINA, Nena et al.) }\end{array}$ & $\begin{array}{l}\text { Prisão Estadual para Mulheres do Vale (VSPW) na } \\
\text { Califórnia } \\
\text { As mulheres foram randomizadas para um programa de } \\
\text { tratamento sensível ao gênero (GRT) usando currículos } \\
\text { manualizados }\end{array}$ \\
\hline 2012 & $\begin{array}{l}\text { Carceral politics as gender justice? The } \\
\text { "traffic in women" and neoliberal } \\
\text { circuits of crime, sex, and rights } \\
\text { (BERNSTEIN, Elizabeth.) }\end{array}$ & $\begin{array}{l}\text { Pesquisa realizada nas prisões dos EUA } \\
\text { Pesquisa etnográfica }\end{array}$ \\
\hline 2014 & $\begin{array}{l}\text { Who benefits from gender-sensitive } \\
\text { treatment? Accounting for abuse } \\
\text { history on longitudinal outcomes for } \\
\text { women in prison } \\
\text { (SAXENA, ET AL.) }\end{array}$ & $\begin{array}{l}\text { Valle State Prison - Califórnia } \\
\text { Método de regressão longitudinal, teste de efeito de } \\
\text { interação, observação participante. }\end{array}$ \\
\hline 2014 & $\begin{array}{l}\text { Predictors of drug use in prison among } \\
\text { women convicted of violent crimes } \\
\text { (BALTIERI , D Antônio) }\end{array}$ & $\begin{array}{l}\text { Penitenciária de Santana, Estado de São Paulo, Brasil } \\
\text { Estatística descritiva e regressão logística multivariada. }\end{array}$ \\
\hline 2015 & $\begin{array}{l}\text { What words can do: } \\
\text { the challenge of representing women in } \\
\text { prison and their writings } \\
\text { (HINSHAW, Wendy Walters) }\end{array}$ & $\begin{array}{l}\text { Recorte mundial } \\
\text { O artigo defende métodos para representar as mulheres } \\
\text { encarceradas e seus escritos que resistem às } \\
\text { subjetividades comuns }\end{array}$ \\
\hline
\end{tabular}

Geopauta, Vitória da Conquista, ISSN: 2594-5033, V. 4, n.3, 2020, p.(255-273) http://periodicos2.uesb.br/index.php/geo, 
What words can do: the challenge of representing women in

2016 prison and their writings

(HINSHAW, Wendy Walters)

Prison: narratives of post-traumatic growth among prisoners

(GINNEKEN, E.)

2016

2016

Becoming a mother in prison

(ABBOLT, L.)

Maintaining the mother-child relationship within the Irish prison system: the practitioner perspective (S. O'MALLEY \& C. DEVANEY)

Organized crime and violence against

2016 women: the official discourse and public perception (LIRA, et al.)

Support for women prisoners who hurt

2017 themselves: exploring the strategies of the prison staff (WALKER et al)

In their own words: Women describe

2017 their use of force, resulting in courtordered intervention (LARANCE, et al)

$\mathrm{Al}$ explorar la agencia de las mujeres

2017 encarceladas por sus experiencias amorosas

(CALVO, M.E.)

Gender differences in social support

2017 experiences between men and women releasing from prison (PETTUS-DAVIS et al)

Crimen feminista, investigación y arrestos de mujeres en España (ALMEIDA SAMARANCH, E.A Et. Al.)
Reino Unido, Universidade Liverpool Hope

Empregou interpretação fenomenológica por meio de entrevistas semiestruturadas

\section{África subsaariana}

Revisão bibliográfica e observação participante Estudo feito na Inglaterra e no País de Gales (Universidade of Hertfordshire)

Estudo qualitativo, com entrevista semiestruturadas Sistema penal Irlandês

Estudo feito por meio de entrevistas das encarceradas e dos trabalhadores

Cidade do México

Pesquisa qualitativa-documental, e quantitativa;

$$
\text { Estudo realizado na Inglaterra }
$$

Foram feitas entrevistas com funcionários das prisões

Estudo realizado na cidade de Michigan - EUA

A metodologia desta pesquisa é estudo de caso

Prisão Nanclares de Oca (Alava). Espanha

Pesquisa qualitativa com entrevistas semi-estruturadas e observação participante

Pesquisa realizada nos EUA pelas Universidade de Washington e Florida

Utilizou-se por meio pesquisa transversal para administrar psicossociais validados

Espanha

Pesquisa documental

El lugar social de las mujeres en el crimen: una vista panorámica de América Latina

2017 (SILVA, M.B. \& IGREJA, R.L.)

Female crime: a comparative study between statistical data on women

2017 detained in Brazil and Argentina (ALVES, J.S.A.)

HIV and viral hepatitis Among the main populations incarcerated

(WIRTZ, ET AL.)

Maternidad encarcelada: análisis feminista de las consecuencias

2018 personales, familiares y sociales en mujeres privadas de libertad. (HERNÁNDEZ, P.C.)

\section{Estudo no Brasil e México}

Estudo baseado em pesquisa bibliográfica e base de dados e informações

Estudo no Brasil e Argentina

Análise histórica, e analítica

Recorte global

Revisão sistêmica e meta-análise de publicações pelo processo de peer-review (2005 a 2015)

Estudo realizado na Catalunha

Basearam-se em entrevistas semiestruturadas e pesquisas documentais

Women in Prison with Traumatic Brain Injury: Prevalence, Mechanism, and

Estudo realizado na Nova Zelândia

Geopauta, Vitória da Conquista, ISSN: 2594-5033, V. 4, n.3, 2020, p.(255-273) http://periodicos2.uesb.br/index.php/geo, 
2018

\begin{tabular}{|c|c|}
\hline & (WOOLHOUSE, R. et al.) \\
\hline 2019 & $\begin{array}{l}\text { Anaconda, jet fuel, white robes and } \\
\text { Miaow Miaow: the prisoners' argot }\end{array}$ \\
\hline & (MOSHE, K.D. \& EINAT,E.) \\
\hline 2019 & $\begin{array}{l}\text { The role of parental status and } \\
\text { involvement in sentence sentences: a } \\
\text { comparison between men and women } \\
\text { sentenced to prison } \\
\text { (TASCA et al.) }\end{array}$ \\
\hline 2019 & $\begin{array}{c}\text { The arrest warrant: is it just a matter of } \\
\text { security? With regard to the case of } \\
\text { female prisons } \\
\text { (MANONELLES, A.B.) }\end{array}$ \\
\hline 2019 & $\begin{array}{l}\text { Domesticity, responsibility and forms } \\
\text { of agency: meanings and uses of labor } \\
\text { prison for women in the City of Santa } \\
\text { Fé, Argentina } \\
\text { (NOEL, et al.) }\end{array}$ \\
\hline 2019 & $\begin{array}{c}\text { Assessing Seeking Security for Women } \\
\text { in Prison: A Randomized Controlled } \\
\text { Study } \\
\text { (TRIPODI, et al.) }\end{array}$ \\
\hline
\end{tabular}

Utilizaram-se de entrevistas Estudo feito no Israel (Neve Tirza prisão

Estudo qualitativo com participação empírica

$$
\text { Pesquisa realizada no Arizona- EUA }
$$

Estudo documental

\section{Chicago, EUA}

Revisão bibliográfica e discussões a partir de seminários

Cidade de Santa Fé, Argentina

Pesquisa abordagem descritiva, e entrevistas

O estudo realizado na prisão de segurança nível máximo/médio na Carolina do Norte, EUA

Estudo quantitativo e de controle experimental

Fonte: Elaborado pelos autores, 2019. Levantamento bibliográfico (2018-19)

Imporante frisar, que a política de superencarceramento (Gráfico 06) norte-americana é utilizada como instrumento de controle das massas mais vulneráveis socialmente e dos imigrantes (DANIN, 2019).

Gráfico 06 - Série populacional carcerária norte-americana (1925-2015)



Fonte: Danin, 2019. 
Entre as principais metodologias utilizadas nos artigos estrangeiros (Gráfico 07), estão as pesquisas desenvolvidas através de entrevistas com cerca de $32 \%$ dos artigos; seguidos de artigos com metodologia documental/bibliográfica com 24\%; Estudos de casos, etnográficos e de análise histórica representam $4 \%$ do universo amostral.

Gráfico 7 - Percentual das metodologias utilizadas nos artigos.

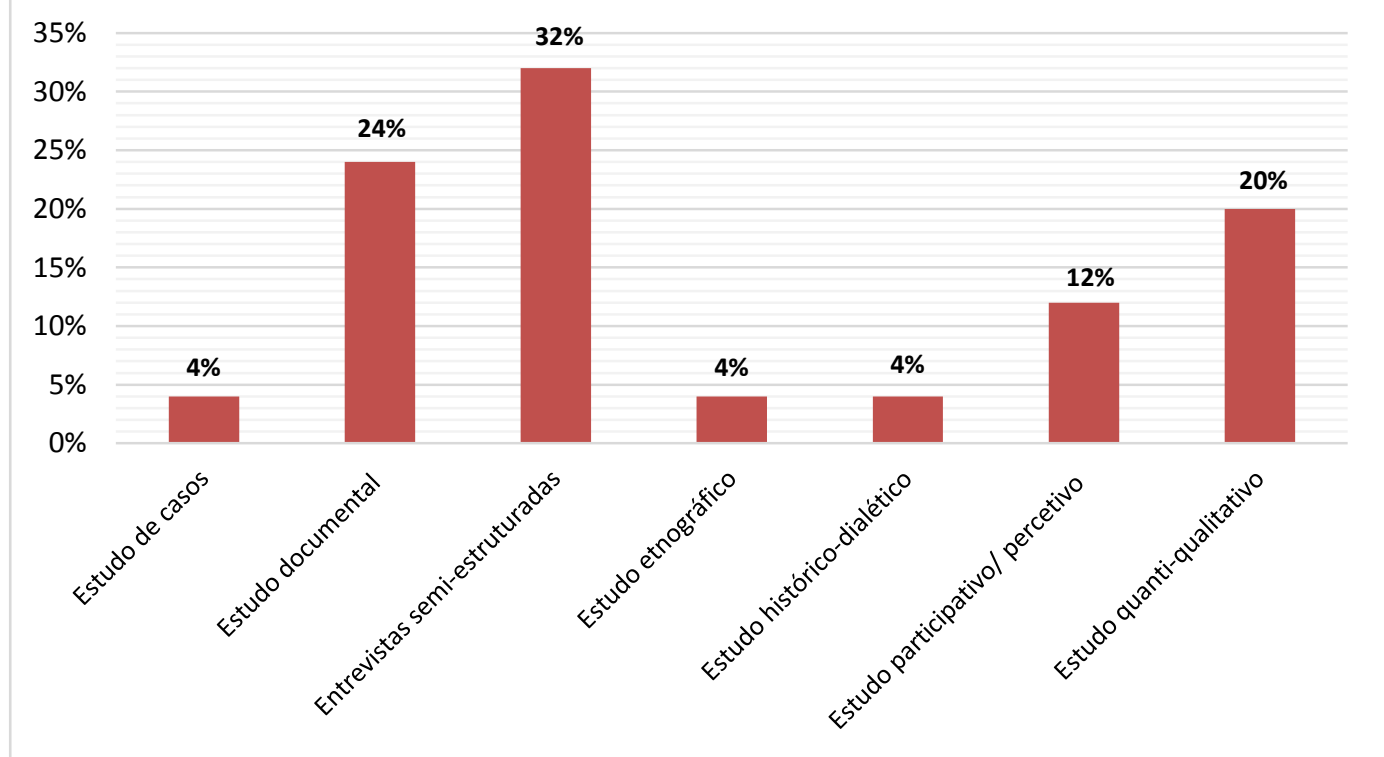

Fonte: Elaborado pela autora, 2020. Levantamento bibliográfico (2018-19)

Os estudos apontam propostas necessárias para melhorias e ressocialização das apenadas nos sistemas prisionais femininos tanto no Brasil quanto em outros países (Quadro 3):

Quadro 03 - Propostas ligadas ao Sistema prisional.

a) A vulnerabilidade de mulheres que são mães e/ou gestantes no sistema prisional e a exposição dos seus filhos a sofrimentos psíquicos e morais

b) A necessidade de implementação de políticas públicas específicas para prevenção de situações de vulnerabilidade de mulheres para o ingresso no tráfico de drogas

Importância de analisar e avaliar as instituições prisionais para mulheres a partir das experiências e olhares das presas

d) Necessidade da ressocialização na perspectiva dos Direitos Humanos; necessidade das penitenciárias se adequarem para além do caráter punitivo e especificidade da mulher encarcerada por meio da efetividade e adequações as realidades atuais da Lei de Execução Penal no 7.210 de 1984

e) As experiências da maternidade dentro dos sistemas prisionais; as desigualdades entre o benefício das visitas intimas de homens e mulheres, visto que o homem tem mais acesso a esse benefício que as apenadas, até sendo a partir dos entraves impostos pelos próprios estabelecimentos prisionais.
FERRARI, F., (2010);

PONTES, D. (2018);

HERNÁNDEZ, P., (2018);

ABBOLT, L, (2016)

LOPES, et. Al., (2010);

SILVA, M., (2017)

IGREJA, L., (2017)

MINZON, et. Al, (2010);

WALKER et al, (2017),

SAMARANCH, E., (2017);

CÚNICO, et al., (2019);

ALVES, J., (2017)

OLIVEIRA e SANTOS (2012);

DAVIM, e LIMA (2016);

DIUANA, et al. (2017);

CARVALHAES, et al. (2018);

GONÇALVES et al. (2018).

Geopauta, Vitória da Conquista, ISSN: 2594-5033, V. 4, n.3, 2020, p.(255-273) http://periodicos2.uesb.br/index.php/geo, 
f) Necessidade da superação da desigualdade de gênero inclusive dentro dos sistemas prisionais, e como os agentes midiáticos transmitem esses papéis e ideologias; Superação da desigualdade de renda para a redução do ingresso das mulheres aos crimes

g) A mídia brasileira aborda a criminalidade feminina, visto que a mídia tem muito impacto na construção e controle de ideologias e práticas discursivas, sendo também mecanismo de coesão e poder sobre subjetividade das pessoas
MIYAMOTO, Y. e KROHLING, A., (2012);

ALVES, D., (2017);

HINSHAW, W., (2016);

NOEL, et al., (2019)

CARVALHAES, et al (2018)

Fonte: Elaborado pelos autores, 2020. Levantamento bibliográfico (2018-19)

\section{CONSIDERAÇÕES FINAIS}

A partir deste estudo desenvolvido, foi possível verificar que:

- Predomínio de metodologias qualitativa/documental no Brasil, com abordagens alicerçadas por entrevistas, com mais de $40 \%$ das abordagens bibliográfica/documental;

- A partir da análise dos estudos brasileiros coletados, observou-se que as regiões Sudeste e Sul apresentaram maior quantitativo entre os trabalhos selecionados com $24 \%$ e $20 \%$, respectivamente. A região nordeste apresentou $18 \%$ dos estudos analisados, com maior concentra no Rio Grande do Norte e na Bahia, enquanto nas regiões Centro-Oeste e Norte, foram as que tiveram as menores distribuições de trabalhos identificados.

- O resultado dos artigos apresentou a necessidade de implementação de políticas públicas que possibilitem alcançar a equidade de homens e mulheres nos sistemas prisionais;

- Observa-se que a temática das mulheres encarceradas ainda sofre certa invisibilidade por parte de diversos setores da sociedade e da Academia, principalmente na observância de abordagens recentes que abordem enfoques Geográficos e da Criminologia Feminista;

- A maioria das mulheres nos sistemas prisionais é punida duplamente pelo delito cometido: tanto pelo sistema prisional, quanto pela sociedade. E que para amenizar esse contexto, reafirmando a necessidade da ressocialização, e de romper barreiras da desigualdade e estigmas;

- Outro aspecto ressaltado, é que em geral a mulher entra no crime por influência do parceiro íntimo, relacionados ao tráfico de drogas;

Por fim, salienta-se a necessidade do desenvolvimento de mais pesquisas com a finalidade de desenvolver metodologias e estudo, capazes de subsidiar o desenvolvimento de políticas públicas, mas aproximadas com a realidade das mulheres encarceradas.

\section{REFERÊNCIAS}


ALVES, D. Rés negras, juízes brancos: Uma análise da interseccionalidade de gênero, raça e classe na produção da punição em uma prisão paulistana. Fundácion DialNet. 2017.

ABBOTT, L. Becoming a mother in prison. The Practicing Midwife, 2016.

ANDRADE, U. S.; FERREIRA, F. F. Crise no sistema penitenciário brasileiro: capitalismo, desigualdade social e prisão. Revista Psicologia, Diversidade e Saúde. 2016.

ANDRADE N.; C. ALVES, J. ARAÚJO. Direito ao nome e identidade de gênero no Brasil e na Argentina. Jus Gentium, v. 12, n. 6, p. 65-90, 2015.

ALMEDA, E.; DI NELLA, D.; NAVARRO, C. Mujeres, cárceles y drogas: datos y reflexiones (Women, Prisons and Drugs: Data and Reflections). Oñati Socio-legal series, v. 2, n. 6, 2012.

ALKER, T. et al. Supporting imprisoned women who self-harm: exploring prison staff strategies. Journal of Criminal Psychology, 2016.

BALTIERI, D. Predictors of drug use in prison among women convicted of violent crimes, Criminal behavior and mental health. Pubmed. 2014.

BERNSTEIN, E. Prison policies like gender justice? The "trafficking in women" and the neoliberal circuits of crime, sex and rights. Teoria e sociedade, v. 41. 2012.

BOITEUX, L. Encarceramento feminino e seletividade penal. Revista Rede Justiça Criminal, $9^{\circ}$ Ed. 2018.

CARCERÁRIA, Pastoral, et al. Relatório sobre mulheres encarceradas no Brasil. Acessado em: 14 de fevereiro de 2020. Disponível: at: asbrad. com.

br/conteúdo/relatório_oea. pdf, 2007.

CARCERÁRIA, Pastoral, et al . Serviço Ecumênico de Militância nas Prisões, Pastoral Carcerária Nacional. Brasil. Resource document. 2015. Acessado em: 09 de janeiro de 2020. Disponível em: https://carceraria.org.br/a-pastoral-carceraria

CARDOSO, S. GONZAGA, M. Sentidos da maternidade na prisão: um estudo empírico na colônia penal feminina de buíque/PE. vol. 02, $\mathrm{n}^{\circ} .55$, Curitiba, 2019.

CARVALHO, S. Processos de criminalização e a participação feminina no tráfico de drogas. Plural, v. 26, n. 1, p. 103-132, 2019.

CLAUS, W. et al. Domesticidad, responsabilização e formas de agenciamiento. sentidos e usos do trabajo carcelario na prisão de mujeres da cidade de Santa Fe, Argentina. Astrolábio, n. 23, p. 53-79, 2019.

CARVALHO, D.; MAYORGA, C. Contribuições feministas para os estudos acerca do aprisionamento de mulheres. Estudos Feministas, 2017.

CARVALHAES, F.; TONELI, M.; MANSANO, S. Mulheres no crime: análise sobre enunciados difundidos pela mídia brasileira. Psicologia \& Sociedade, 2018. 
CUNHA, E. Ressocialização: O desafio da educação no sistema prisional feminino. Cadernos Cedes, 2010

CÚNICO, S.; STREY, M.; COSTA, A. Quem está no comando? Mulher de bandido e os paradoxos da submissão. Revista Estudos Feministas, v. 27, n. 2, 2019.

DAVIM, B.; LIMA, C. Criminalidade Feminina: Desestabilidade familiar e as várias faces do abandono. Revista Transgressões, v. 4, n. 2, p. 138-157, 2016.

DA SILVA, M.; IGREJA, R. O lugar social da mulher na criminalidade: um olhar panorâmico sobre a América Latina. 2017.

DE CALVO M.; E. Explorando la agencia de las mujeres encarceladas a través de sus experiencias amorosas. Papers. Revista de Sociología, v. 102, n. 2, p. 311-335, 2017.

DEPEN. Levantamento Nacional de Informações Penitenciárias - Infopen Mulheres, $\mathbf{2}^{\mathrm{a}}$ edição. Relatório temático sobre as mulheres privadas de liberdade. Ministério da Justiça e da Segurança Pública, 2019. Acessado em: 14.04.2019 Disponível em:

http://depen.gov.br/DEPEN/depen/sisdepen/infopen-mulheres/infopenmulheres_arte_07-0318.pdf

DIUANA, V.; CORRÊA, M.; VENTURA, M. Mulheres nas prisões brasileiras: Tensões entre a ordem disciplinar punitiva e as prescrições da Maternidade. Physis: Revista de Saúde Coletiva, 2017.

FERRARI, Ilka Franco. Mulheres encarceradas: elas, seus filhos e nossas políticas. Revista Mal-estar E Subjetividade, 2010.

GONÇALVES, V; COUTINHO, C. A política criminal de drogas e o seu impacto nos índices de encarceramento feminino. Direito - Estudo e ensino (Pós-graduação) Encontros Nacionais. 2. Assistência. 3. Isonomia. XXVII Encontro Nacional do CONPEDI (Porto Alegre, Brasil), 2018.

HERNÁNDEZ, P. Maternidad encarcelada: análisis feminista de las consecuencias personales, familiares y sociales en mujeres privadas de libertad. Revista Temas Sociológicos, 2018.

HINSHAW, W.; JACOBI, T. What words can they do: The challenge to interpret as women in prison and their writings. Feminist formations. 2015.

JORGE, M.; et al. A produção de sintomas como silenciamento da violência. 2009. Tese de Doutorado. Fundação Oswaldo Cruz - Fiocruz. 2019. Acessado em 15 de março de 2020. Disponível em:

https://bvssp.icict.fiocruz.br/pdf/25500_Marco_Aurelio_Soares_Jorge_2009.pdf

LARANCE, L.; MILLER, L. In her own words: Women describe their use of force resulting in court-ordered intervention. Violence against women, 2017.

LOPES, R.; DE MELO, D.; DE LIMA A. Mulheres encarceradas e fatores associados a drogas e crimes. Ciências \& Cognição, v. 15, n. 2, 2010. 
LAIER, M. Atrás das grades: Questões de gênero na prisão feminina de João Pessoa. Sociedade em Debate, 2016.

MACHADO, A; SOUZA, A.; SOUZA, M. Sistema Penitenciário Brasileiro - Origem, Atualidade e Exemplos Funcionais. Revista do Curso de Direito da Faculdade de Humanidades e Direito, v. 10, n. 10, p. 201-212, 2013.

MACHADO, J. Maternidade encarcerada: uma análise da substituição da prisão preventiva pela domiciliar das mulheres gestantes e com filhos menores de 12 anos no Tribunal de Justiça do Estado do Rio de Janeiro. 2016.

MESSINA, N. et al. A Randomized Experimental Study of Gender-Responsive Substance Abuse Treatment for Women in Prison. Substance Abuse Treatment Journal, 2010.

MIYAMOTO, Y.; KROHLING, A.; Sistema prisional brasileiro sob a perspectiva de gênero: invisibilidade e desigualdade social da mulher encarcerada. Revista Direito, Estado e Sociedade, n. 40, 2012.

MINZON, C.; DANNER, G; BARRETO, D. Sistema prisional: conhecendo as vivências da mulher inserida neste contexto. Akrópolis-Revista de Ciências Humanas da UNIPAR, 2010.

MOSHE, K.; EINAT, T. ANACONDA, J. White Vestes e Miaow Miaow: O Argot das Prisioneiras. The Prison Journal , v. 99, n. 6, p. 683-705, 2019.

NASCIMENTO, L. A (In) visibilidade da mulher Criminosa e a desigualdade de gênero no espaço da prisão: uma análise da vivência das mulheres em situação de prisão no Complexo Penal Estadual Agrícola Dro Mário Negócio Em Mossoró/Rn. Revista Transgressões, v. 1, n. 2, p. 164-185, 2015.

OLIVEIRA, H C. A falência da política carcerária brasileira. III Jornada Internacional de Políticas Públicas Questão Social e Desenvolvimento No Século XX (2007).

OLIVEIRA, M. Desigualdade de gênero no sistema prisional: considerações acerca das barreiras à realização de visitas e visitas íntimas às mulheres encarceradas. Caderno espaço feminino, v. 25, n. 1, 2012.

OMS. ORGANIZAÇÃO MUNDIAL DE SAÚDE (CH). WHO Geneva. Relatório mundial sobre a prevenção da violência. 2015. Disponível em: https://nev.prp.usp.br/wpcontent/uploads/2015/11/1579-VIP-Main-report-Pt-Br-26-10-2015.

PAIVA, P. Mulheres encarceradas: cartas e entrevistas sobre a vida na prisão (20042014). Revista Humanidades em Perspectivas. vol.2 n.1. 2019.

PETTUS-DAVIS, C. et al. Gender differences in experiences of social support among men and women releasing from prison. Journal of Social and Personal Relationships, 2018.

PONTES, D. Drogas, crime organizado, mães e filhos, e a conversão de prisão preventiva em domiciliar. Revista da AJURIS - Porto Alegre, v. 45, n. 144, Junho, 2018. 
RAMOS, L. O reflexo da criminalização das mulheres delinqüentes pela ausência de políticas públicas de gênero, em questão: os direitos sexuais e reprodutivos. Anais do XIX Encontro Nacional do CONPEDI, Fortaleza/CE, jun. 2010.

RAMOS L.; GONZÁLEZ, I.; SALTIJERAL MÉNDEZ, M. Crimen organizado y violencia contra las mujeres: discurso oficial y percepción ciudadana. Revista mexicana de sociología, v. 78, n. 4, p. 655-684, 2016.

RUDNICKI, D.; NEUBÜSER, M. Direitos Humanos e Superlotação no Presídio Feminino de porto Alegre/Human Rights and Overcrowding in the Women's Prison in Porto Alegre. Revista Direito, Estado e Sociedade, 48. 2016.

RUEDIGER, M.; SANCHES, D. Encarceramento feminino. 2018. Fundação Getúlio Vargas - FGV. Acessado em: 19 de maio de 2020. Disponível em:

http://bibliotecadigital.fgv.br/dspace/bitstream/handle/10438/25741/Encarceramento\%20femi nino.pdf? sequence $=1 \&$ is Allowed $=\mathrm{y}$

SANTORO, A; PEREIRA, A.; LARA, M. Gênero e prisão: o encarceramento de mulheres no sistema penitenciário brasileiro pelo crime de tráfico de drogas. Meritum, revista de Direito da Universidade FUMEC, 2018.

SAXENA, P.; MESSINA, P.; GRELLA, E. Who benefits from gender-responsive treatment? Accounting for abuse history on longitudinal outcomes for women in prison. Criminal Justice and Behavior, 2014.

SAMARANCH, E. Feminist Criminologies, Research and Women's Prisons in Spain. Papers-Revista de Sociologia, 2017.

SINEAD O'Malley; CARMEL D. Maintaining the mother-child relationship within the Irish prison system: the practitioner perspective. Child Care in Practice. 2016.

SILVA, S. Mulheres e criminalidade: Aspectos de uma inclusão enviesada. Revista Transgressões, v. 5, n. 2, p. 104-118, 2017.

SOARES, G.; FÉLIX-SILVA, A.; FIGUEIRÓ, M. Teatro-menor: cartografia em arte e experimentação de mulheres em situação de cárcere. Psicologia \& Sociedade, v. 26, p. 89$99,2014$.

SOUZA, T.; SANTANA, F.; MARTINS, T. Violência contra a mulher, polícia civil e políticas públicas. Revista Pesquisas e Práticas Psicossociais, 2018.

TOURINHO, L.; SOTERO, P.; AMORIM, A. Condições precárias de saúde na ala feminina do Presídio Nilton Gonçalves: uma história de abandono e sofrimento. Revista Direitos Humanos e Democracia, 2016.

TRIPODI, J., et al. Evaluating seeking safety for women in prison: A randomized controlled trial. Research on Social Work Practice. 2019.

TASCA, M., et al. The Role of Parental Status and Involvement in Sentence Length Decisions: A Comparison of Men and Women Sentenced to Prison. Crime \& Delinquency, 2019. 
VAN GINNEKEN, F. Making sense of imprisonment: Narratives of posttraumatic growth among female prisoners. International journal of offender therapy and comparative criminology, v. 60, n. 2, p. 208-227, 2016.

CARDOSO C.; OLIVEIRA, M. Narrativas sobre experiências de leitura em uma cadeia pública feminina: fronteiras borradas. Revista Brasileira de Pesquisa (Auto) biográfica, 2019.

WIRTZ, L., et al. HIV and viral hepatitis among imprisoned key populations. Epidemiologic reviews, 2018.

WORLD PRISION BRIEF. World Prision Brief. 2016 Acesso em: 15 Novembro 2019 Disponível em: http://www. prisonstudies.org/world-prison-brief.

WOLA. Mulheres, políticas de drogas e encarceramento: Um guia para a reforma em políticas na América Latina e no Caribe. The Washington Office on Latin America. Open Society Fouqndations e Fundación Libra. 2018

WOOLHOUSE, R.; MCKINLAY, A.; GRACE, C. Women prisoners with traumatic brain injury: prevalence, mechanism and impact on mental health. International Journal of. 2018. 